\title{
Calix[4]arene Embedded Polyamide Supported Liquid Membrane for Separation of Heavy Metals from Aqueous Solutions
}

\author{
Seydahmet Cay ${ }^{1, a, *}$, Serkan Sayin ${ }^{1, b}$, Mehmet Soner Engin ${ }^{2, c}$ \\ ${ }^{I}$ Department of Environmental Engineering, Faculty of Engineering, Giresun University, 28200 Güre/Giresun, Turkey \\ ${ }^{2}$ Department of Food Engineering, Faculty of Engineering, Giresun University, 28200 Güre/Giresun, Turkey
}

*Corresponding author

A R T I C L E I N F O
Research Article
Received : 06/11/2019
Accepted : 01/01/2020

Keywords:

Calixarene

Characterization

Supported liquid membrane

Trace metal

Characterization of membrane
A B S T R A C T

In this study, we aimed to prepare new calixaren embedded mercapto groups supported liquid membranes and to use them in the transport of heavy metals. For this purpose 5,11,17,23-tetra-tertbutyl-25,27-bis(3-thiol-1-oxypropane)-26,28-dihydroxylcalix[4]arene was synthesized. The synthesized calixarene compounds were fully characterized by spectroscopic and the other techniques. The prepared compounds were supported polyamide liquid membranes and obtained calix[4]aren embedded supported liquid membranes (C@PSMs). The characterization of C@PSM was carried out by FTIR, TGA and elemental analysis techniques. Transport experiments were carried out with $\mathrm{Pb}(\mathrm{II}), \mathrm{Cd}(\mathrm{II})$ and $\mathrm{Zn}$ (II) as trace metals, to transport from donor phase to accept phase. From the results, it was calculated flux (J) and recovery (RF) values. The affinity (the percentage of metal ion transferred from the source solution) of a PIM towards a range of divalent cations was found to follow the order $\mathrm{Zn}$ (II) $>\mathrm{Cd}(\mathrm{II})>\mathrm{Pb}$ (II).

seydahmet.cay@giresun.edu.tr (iD) https://orcid.org/0000-0003-0045-8217 c@soner.engin@giresun.edu.tr

\section{Introduction}

It is known that environmental pollution is caused by very high levels of heavy metal pollution from industrial sources (Cay et al., 2004; Ugur et al., 2015). Technologies used in various branches of industry require the use of large amounts of heavy metals, if introduced directly or indirectly to the environment, causing the potential to contaminate both surface and groundwater (Konczyk et al., 2016; Wu et al., 2016). Heavy metals are toxic substances known to trigger adverse health effects, including cardiovascular diseases, neurological disorders, diabetes, hearing loss, hematological and immunological disorders, and various types of cancer in humans (Kir et al., 2015).

There are many ways to extract heavy metals from waste waters. Some of these ways are chemical precipitation, biosorption, adsorption, ion exchange, electrolysis, distillation, reverse osmosis, ultrafiltration, solvent extraction, and liquid membranes (Sap et al., 2012). The increasing severity of environmental regulations affecting the discharge of effluents has created a sustained interest in the development of novel technologies that could improve the efficiency of the separation of toxic materials from very dilute solutions (Engin et al., 2019).
According to many studies, liquid membranes have become an attractive alternative to selective separation and low concentration of target metals (Konczyk et al., 2016). These membranes include emulsion liquid membranes, supported liquid membranes, bulk liquid membranes and polymer inclusion membranes (Ugur et al., 2015). Among these, polymer inclusion membranes and support liquid membranes stands out due to high transport rates, good selectivity and long-term stability. Supported liquid membranes are, in particular, considered to be one of the types of liquid membranes suitable for the removal and recovery of toxic metals from aqueous solutions. The use of supported liquid membranes containing carrier and microporous membranes has been proposed as an alternative to solvent extraction processes for the selective separation and concentration of metal ions. A supported liquid membrane contains an organic carrier solution immobilized in a porous hydrophobic support membrane. Since they are stable under the test conditions used and have suitable chemical properties, any membrane material can be used as the support membrane. Indeed, highly stable materials such as polypropylene, polyethylene, polysulfone, polyamide, and polyvinylidene fluoride are often used as supports (Kir et al., 2015). 
The calixarene derivatives have been used as extractant for the removal of toxic ions. They are also form selective and stable complexes with anions, cations or neutral molecules (Sayin et al., 2011). Because of the specificity of the structure and the diversity of the derivative, calixarenes have attractive expectations for chemical sensors, ion transport, separation and analysis, recovery of precious metals, molecular recognition and incorporation, molecular catalysis and enzyme simulation, ion selective electrodes. Research on calixaren is particularly important for chemistry, environmental chemistry, the development of life chemistry and structural chemistry in supramolecular chemistry (Tabakci and Yilmaz, 2008; Liu and Zhong, 2018).

In this paper, the affinity of supported liquid membranes containing mercapto groups derivative towards heavy metals from aqueous solutions. For this purpose; ptert-butylcalix[4]arene, p-tert-butylphenol and formaldehyde in basic environment by condensation reaction was synthesized. The synthesized p-tertbutylcalix[4]arene in the presence of $\mathrm{K}_{2} \mathrm{CO}_{3}$ into the reaction with 1,3- dibromopropane derivative of dialkyl bromide of calixaren was synthesized. The obtained derivative of dialkyl bromide of calixarene into the reaction with thiourea and dialkylthiol functional of calixarene was synthesized. The synthesized calixarene compounds were fully characterized by spectroscopic and the other techniques. The prepared compounds were supported different liquid membranes especially polyamide and obtained calix[4]arene embedded supported liquid membranes (C@PSMs). The characterization of C@PSM was carried out by FTIR, TGA and elemental analysis techniques. Transport experiments were carried out with $\mathrm{Pb}(\mathrm{II}), \mathrm{Cd}(\mathrm{II})$ and $\mathrm{Zn}$ (II) as heavy metals, to transport from donor phase to accept phase. From the results, it was calculated flux $(\mathrm{J})$ and recovery $(\mathrm{RF})$ values.

\section{Material and Method}

\section{Chemicals and Materials}

All of the starting materials and reagents were obtained from Merck (Merck, Darmstadt, Germany) and Aldrich companies (Aldrich; Steinheim, Germany) and used without further purification. Ultra-pure water obtained from a Milli-Q (Millipore Corp.) was used to prepare all solutions. Melting points were determined using a Gallenkamp apparatus in a closed capillary tube. NMR spectra were recorded on a Bruker $400 \mathrm{MHz}$ spectrometer. TLC silica gel plates ( $\mathrm{SiO} 2$, Merck PF254) were used for analytical thin layer chromatography studies. A Burker (820-MS) Inductive Coupled Plasma Mass Spectrometer (ICP-MS) was used to determine the heavy metals transfer of the novel C@PSM.

\section{Synthesis}

The compounds p-tert-butylcalix[4] arene (1), 5,11,17,23-tetra-tert-butyl-25,27-bis (bromopropoxy) -26,28-dihydroxycycline [4] arene (2) and 5,11,17,23tetra-tert-butyl-25,27-bis(3-thiol-1-oxypropane)-26,28dihydroxycalix[4]arene (3) were synthesized according to the published procedures (Gutsche, 1990; Sayin et al., 2011; Demirkol et al., 2014). 5,11,17,23-tetra-tert-butyl-25,27-bis(3-thiol-1oxypropane)-26,28-dihydroxycalix [4]arene (3)

Yield: $40 \%$, m. p.: $203-205^{\circ} \mathrm{C} .{ }^{1} \mathrm{H}-\mathrm{NMR}(400 \mathrm{MHz}$, $\left.\mathrm{CHCl}_{3}\right): \delta 9.13(\mathrm{~s}, 2 \mathrm{H},-\mathrm{OH}), 7.07(\mathrm{~s}, 4 \mathrm{H}, \mathrm{ArH}), 7.01(\mathrm{~s}, 4 \mathrm{H}$, $\mathrm{ArH}), 4.23$ (d, 4H, $\left.J=12.8 \mathrm{~Hz}, \mathrm{Ar}-\mathrm{CH}_{2}-\mathrm{Ar}\right), 4.01(\mathrm{t}, 4 \mathrm{H}, J=$ $\left.4.8 \mathrm{~Hz},-\mathrm{CH}_{2}-\mathrm{O}\right), 3.38$ (d, $\left.4 \mathrm{H}, J=12.8 \mathrm{~Hz}, \mathrm{Ar}-\mathrm{CH}_{2}-\mathrm{Ar}\right), 3.24$ (t, $\left.4 \mathrm{H}, J=8.0 \mathrm{~Hz},-\mathrm{CH}_{2}-\mathrm{S}\right), 2.42-2.48\left(\mathrm{~m}, 4 \mathrm{H},-\mathrm{CH}_{2}-\right), 1.57-$ $1.69(\mathrm{~m}, 2 \mathrm{H},-\mathrm{SH}), 1.22\left(\mathrm{~s}, 18 \mathrm{H}, \mathrm{Bu}^{\mathrm{t}}\right), 1.19\left(\mathrm{~s}, 18 \mathrm{H}, \mathrm{Bu}^{\mathrm{t}}\right)$. Anal. calcd. For $\mathrm{C}_{50} \mathrm{H}_{68} \mathrm{O}_{4} \mathrm{~S}_{2}$ : C, 75.33; H, 8.60. Found (\%); C, 75.45; H, 8.79.

\section{Preparation of C@PSM}

Microporous polyamide membrane filter, (NL17, 0.45 $\mu \mathrm{m}, 25 \mathrm{~mm}$ ) was used as the support. Polyamide supported membranes (PSM) were incubated overnight in 5,11,17,23tetra-tert-butyl-25,27-bis(3-thiol-1-oxypropane)- 26,28dihydroxylcalix[4]arene (10 mg) as ion carrier dissolved in chloroform, membrane saturated with carrier solution and provided to achieve a more stable structure. Lastly, before being used in transport experiments, the C@PSM was immersed in distilled water for 2 hours. In the absence of the ion carrier, it did not show a clear flow from the C@PSM with empty experiments for transport.

\section{Characterization}

The characterization of C@PSMs was carried out by Fouirer Transform Infrared spectroscopy (FT-IR), Thermo Gravimetric Analysis (TGA) and elemental analysis techniques.

\section{Transport Experiments}

The aqueous solution transport of heavy metals was performed using a cell of two separable sections made of Teflon (Koseoglu et al., 2010). All measurements were made at room temperature. The feed phase contained heavy metals $\left(10^{4-} \mathrm{M}\right)$ solutions and the receptor phase contained deionized water. Experiments on the transport of heavy metals through the C@PSM from the feed phase to the strip phase were specified for 2 hours each or otherwise. The transport of heavy metals from the feed phase to the strip phase was measured at regular time intervals by taking samples from the feed and strip solutions and analyzed for the analysis of heavy metal concentrations. At the C@PSM / solution interface, the value of the initial flow $\left(\mathrm{J}_{0}, \mathrm{~mol} \mathrm{~m}^{2-}\right.$ $\mathrm{s}^{1-}$ ) was used to evaluate the rate of removal of the C@PSMs and was calculated using the following equation:

$$
\mathrm{J}_{0}=-\left(\frac{\mathrm{V}}{\mathrm{A}}\right)\left(\frac{\mathrm{dC}}{\mathrm{dt}}\right)_{\mathrm{t}=0}=-\left(\frac{\mathrm{V}}{\mathrm{A}}\right)\left(\frac{\mathrm{C}_{\mathrm{t}}-\mathrm{C}_{\mathrm{t}=0}}{\mathrm{t}}\right)
$$

Where, $\mathrm{V}$ is the volume of feed solution $\left(\mathrm{m}^{3}\right)$; $\mathrm{A}$ is the effective contact area of membrane $\left(\mathrm{m}^{2}\right)$; $\mathrm{C}$ is the change in heavy metal concentration over time $\left(\mathrm{molL}^{-1}\right)$; $\mathrm{t}$ is elapsed time (s) (Venkateswaran et al., 2007).

The recovery factors $(\mathrm{RF} \%)$ of the trace metals were calculated from the following equation:

$$
R F \%=\left(1-\frac{C_{r}}{C_{f}}\right) \times 100
$$

$\mathrm{C}_{\mathrm{r}}$ and $\mathrm{C}_{\mathrm{f}}\left(\mathrm{molL}^{-1}\right)$ are dichromate concentrations in the receiver and feed phases, respectively. 


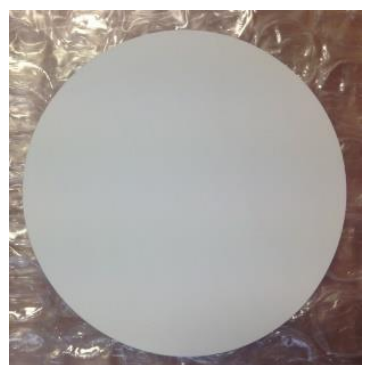

(a)

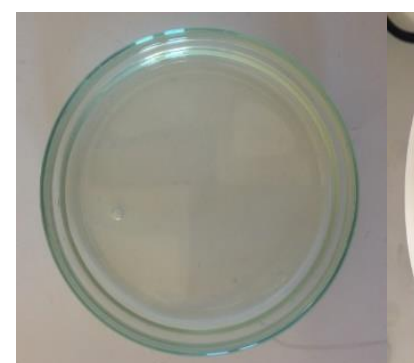

(b)

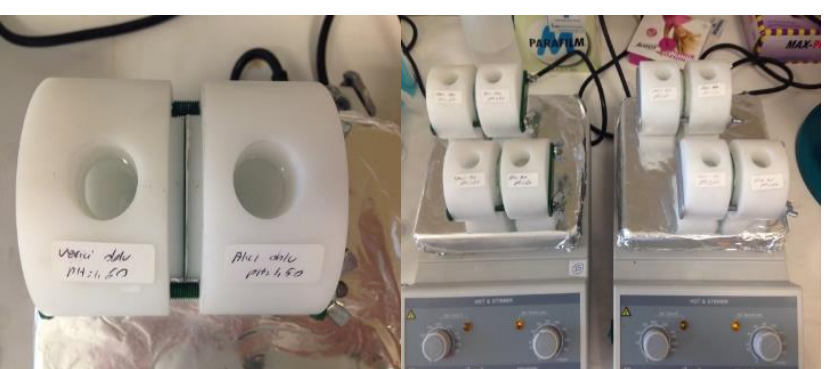

(c) (d)

Figure 1. General procedure a) PSM b) C@PSM c) Donnan dialysis d) Metal transport

\section{Result and Discussion}

\section{Synthesis}

The objective of this articles is to investigate the dichromate anion transport property of a mercapto functionalized calix[4]arene-embedded polymer inclusion membrane. For this purpose, p-tert-butylcalix[4]arene, dialkyl bromide derivative of $p$-tert-butylcalix[4]arene, and 5,11,17,23-tetra-tert-butyl-25,27-bis(3-thiol-1-oxypropane) -26,28-dihydroxylcalix[4]arene (3) were synthesized according to the published literature procedures (Gutsche, 1990; Sayin et al., 2011; Demirkol et al., 2014).

\section{Characterization of C@PSMs}

The infrared spectrum of PSM (Fig. a) and the C@ PSM (Fig. b) were obtained and are shown in Figure 1. When we look at the FT-IR specrum of the C@PSM in which the PSM and the calix[4]arene are absorbed, the characteristic peaks of the calix[4]arene are generally clouded because the intensity of the PSM is greater than the calix[4]arene compound.

Figure 2 demonstrates thermogravimetric analysis (TGA) result of the C@PSMs. The thermal decomposition temperature, at about 242,351 and $483^{\circ} \mathrm{C}$, all corresponds to the high weight loss of mercapto groups calix[4]arene derivative and thermal depolymerization of polyamide for C@PSM.

According to the elemental analysis results of C@ PSM given in Table 1, mercapto groups calix[4]arene derivatives are absorbed into the PSM. From the results, C@PSM contained $0.41 \% \mathrm{~S}$, which shows that $0.26 \mathrm{mmol}$ of mercapto groups calix[4]arene derivatives are present in $1 \mathrm{~g}$ of PSM.

\section{Transport Studies}

\section{Effect of contact time}

The contact time required to achieve equilibrium is an important factor in membrane processes. The contact time required to achieve equilibrium for the metals is shown in Figure 3. In the first few minutes, the uptake of metals was very rapid since there were initially more C@PSM sites available for uptake of metals. As time passed, the metals did not occupy any space and therefore a slow transfer process took place. Therefore, 150 minutes was chosen as the appropriate contact time for the systems.

\section{Effect of $p H$}

It is well known that $\mathrm{pH}$, as well as various physicochemical effects, is an important variable in which membrane surface processes can or can be altered. To observe the effect of this parameter on transport, the C@PSMs were contacted with metal solutions at $\mathrm{pH}$ 2.0-5.5. Lower $\mathrm{pH}$ values (acidic) were not investigated because of change of C@PSMs structure and higher $\mathrm{pH}$ values were not investigated because of the insolubility of the cations, so the best results are measured at $\mathrm{pH}$ 5.5. Also the $\mathrm{pHs}$ of prepared metal solutions are approximately the same value.

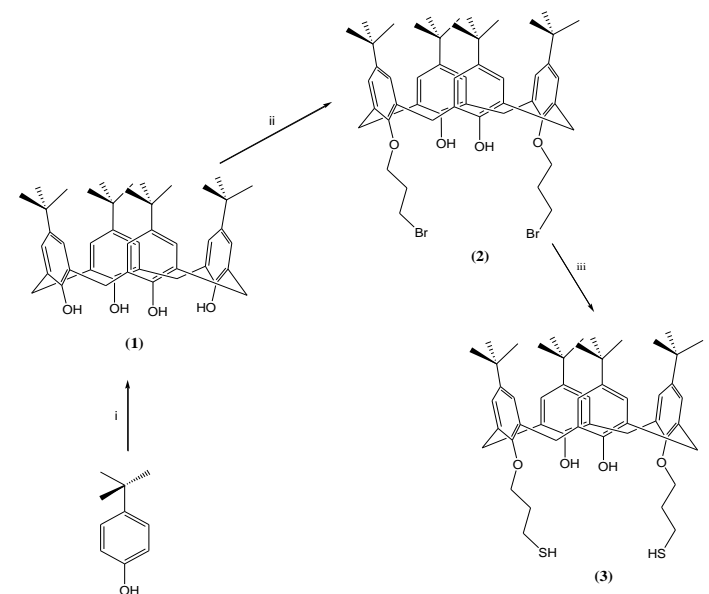

Scheme 1. Synthesis of mercapto-functionalized calix[4]arene derivative (3). Reaction conditions; (i) $\mathrm{HCHO}, \mathrm{NaOH}$; (ii) 1,3-dibromopropane, $\mathrm{K}_{2} \mathrm{CO}_{3}, \mathrm{CH}_{3} \mathrm{CN}$, $\mathrm{NaI}$; (iii) thiourea, $\mathrm{CH}_{3} \mathrm{CN}$, $\mathrm{KOH}$.

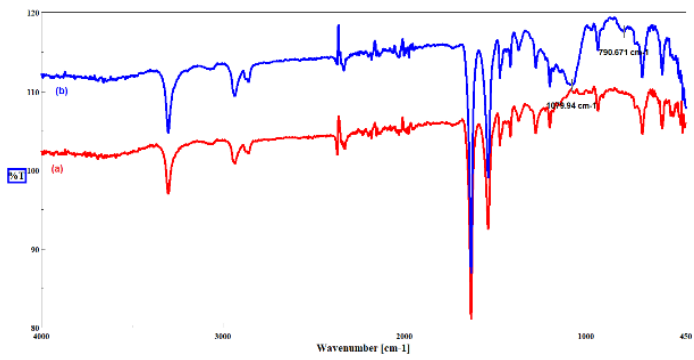

Figure 1. FT-IR of a) PSM b) C@PSM

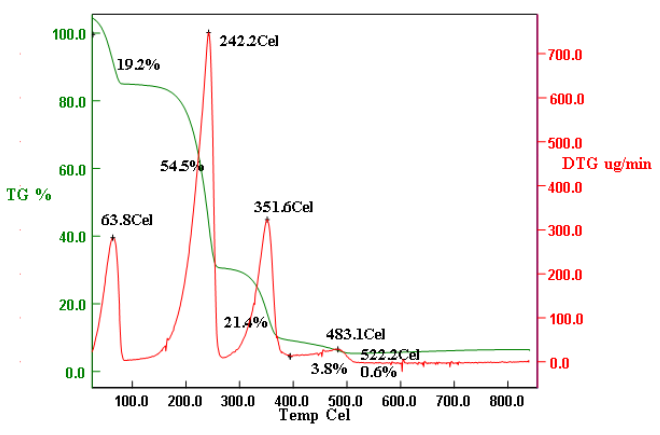

Figure 2. The TGA curves of C@PSM 
Table 1. Elemental analysis results of C@PSM

\begin{tabular}{l|ccccc}
\hline & $\mathrm{C}(\%)$ & $\mathrm{H}(\%)$ & $\mathrm{S}(\%)$ & $\mathrm{N}(\%)$ & ${\text { Immobilized amount of calix[4]arene }(\mathrm{mmol} / \mathrm{g})^{\mathrm{a}}}$ \\
\hline PSM & 39.18 & 3.73 & - & 0.13 & \\
C@ PSM & 39.56 & 3.20 & 0.41 & 0.10 & $\sim 0.26$ \\
\hline
\end{tabular}

${ }^{a}$ Calculated according to the $\mathrm{S}$ content

Table 2. RF and J values of heavy metals for C@PSMs

\begin{tabular}{l|ccc}
\hline & $\mathrm{pH}$ & $\mathrm{J} \times 10^{11}\left(\mathrm{~mol} . \mathrm{cm}^{-2} \cdot \mathrm{s}^{-1}\right)$ & RF values (180 min.) \\
\hline \multirow{3}{*}{$\mathrm{Zn}(\mathrm{II})$} & 2.05 & $0.321( \pm 0.011)$ & 20.161 \\
& 3.05 & $0.528( \pm 0.014)$ & 28.534 \\
& 4.15 & $0.517( \pm 0.004)$ & 29.179 \\
& 5.50 & $0.732( \pm 0.011)$ & 42.755 \\
$\mathrm{Cd}(\mathrm{II})$ & 2.15 & $0.241( \pm 0.008)$ & 20.203 \\
& 3.00 & $0.219( \pm 0.017)$ & 22.429 \\
& 4.15 & $0.306( \pm 0.011)$ & 25.807 \\
$\mathrm{~Pb}(\mathrm{II})$ & 5.40 & $0.430( \pm 0.016)$ & 31.866 \\
& 2.00 & $0.193( \pm 0.021)$ & 20.161 \\
& 3.05 & $0.308( \pm 0.019)$ & 20.959 \\
& 4.20 & $0.327( \pm 0.012)$ & 24.172 \\
\hline
\end{tabular}

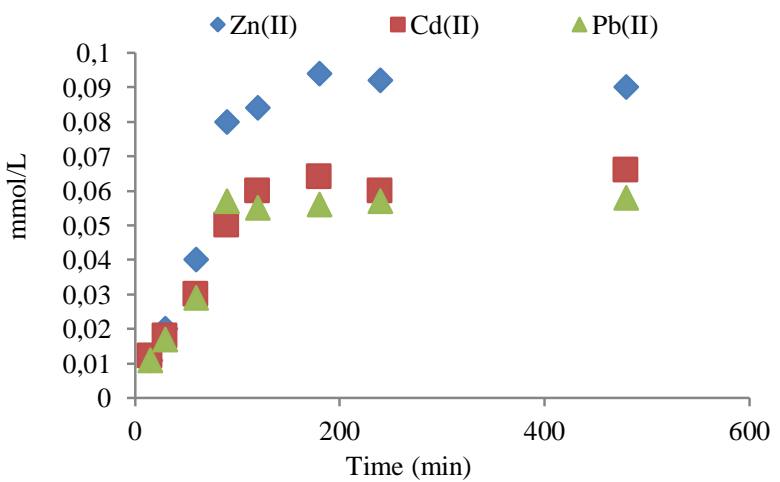

Figure 3. Effect of Contact Time for C@PSM

The RF and flux values of the heavy metals in the different metals were calculated from the time profile and the receiving phase concentration of the first phase technique and the results are given in Table 1 . The results are at $95 \%$ confidence level $(\mathrm{N}=3)$. The $\mathrm{RF}$ values of the $\mathrm{Zn}(\mathrm{II}), \mathrm{Cd}(\mathrm{II})$ and $\mathrm{Pb}$ (II) were also shown in Table 1 . It is seen that the highest flux and RF values of heavy metals are obtained by $\mathrm{Zn}(\mathrm{II})$. Because of the ion radius ( $\mathrm{Zn}$ (II) $0.075 \mathrm{~nm}, \mathrm{Cd}$ (II) $0.095 \mathrm{~nm}, \mathrm{~Pb}$ (II) $0.119 \mathrm{~nm}$ ), the transfer capacities of metal ions were in the same following order $\mathrm{Zn}(\mathrm{II})>\mathrm{Cd}(\mathrm{II})>\mathrm{Pb}(\mathrm{II})$ as in the literature.

Reusability of C@PSMs

To use the membranes at an industrial scale, to make them easy to clean up is necessary. For an effective reuse, a successful regeneration process was applied. For this aim, purified water was used for desorption of metal ions and the transfer capacities of metal ions by the C@PSMs. The $\mathrm{Zn}$ (II) mmol amounts obtained for the number of runs are shown in Figure 4. As shown in Figure 4, when up to four additional regeneration cycles were performed, no decrease of transfer capacity could be measured. When the experiments were completed, no structural deformation of the membranes was observed.

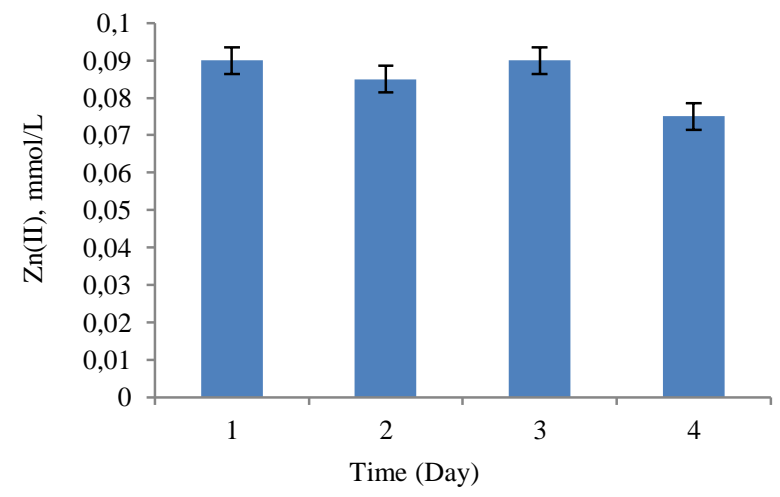

Figure 4. Investigation of the stability of C@PSMs

\section{Conclusion}

The calix[4]arene embedded mercapto groups supported liquid membranes and to use them in the transport of heavy metals. The results are summarized as follows:

- The structure and surface morphology of C@PSMs were determined by FT-IR, TGA and elemental analysis techniques.

- The transfer capacities of the three metal ions under the same conditions was in the following order $\mathrm{Zn}(\mathrm{II})>$ $\mathrm{Cd}(\mathrm{II})>\mathrm{Pb}(\mathrm{II})$.

- As a result of regeneration cycles and four repeated transporting, the C@PSMs retained almost the same transfer ability that indicates that the C@PSMs own good stability.

- For the transfer of metal ions from aqueous solutions in further operations, the experiments conducted in this study provided encouraging results to apply these C@PSMs.

\section{Acknowledgement}

This study was supported by Giresun University (FENBAP-A-140316-71) Scientific Research Project. 


\section{References}

Cay S, Uyanik A, Ozasik A. 2004. Single and binary component adsorption of copper(II) and cadmium(II) from aqueous solutions using tea-industry waste. Separation and Purification Technology, 38(3): 273-280.

Demirkol DO, Yildiz HB, Sayin S, Yilmaz M. 2014. Enzyme immobilization in biosensor constructions: Self-assembled monolayers of calixarenes containing thiols. Rsc Advances, 4(38): 19900-19907.

Engin MS, Sayin, S. Cay, Kir E, Sardohan-Koseoglu T. 2019. Preparation and characterisation of thiol functionalised p-tertbutylcalix[4]arene-embedded polymer inclusion membranes: Performance and selectivity. International Journal of Environmental Analytical Chemistry, 99(11): 1103-1111.

Gutsche CD. 1990. Single step synthesis and properties of calixarenes in calixarenes: A versatile class of macrocyclic compounds, ed. Vicens. In: Topics in inclusion science. pp: 3-37.

Kir E, Yalimli S, Kurtulmus S, Aydin A, Yilmaz H. 2015. Facilitated transport of ni(ii) through supported liquid membranes containing dithiophosphonates as ion carrier. Phosphorus Sulfur, 190(2): 178-190.

Konczyk J, Nowik-Zajac A, Kozlowski CA. 2016. Calixarenebased extractants for heavy metal ions removal from aqueous solutions. Separation Science and Technology, 51(14): 23942410.

Koseoglu TS, Kir E, Ozkorucuklu SP, Karamizrak E. 2010. Preparation and characterization of $\mathrm{p} 2 \mathrm{fan} / \mathrm{pvdf}$ composite cation-exchange membranes for the removal of $\mathrm{cr}(\mathrm{II})$ and $\mathrm{cu}(\mathrm{II})$ by donnan dialysis. Reactive and Functional Polymers, 70(11): 900-907.
Liu YN, Zhong ZM. 2018. Extraction of heavy metals, dichromate anions and rare metals by new calixarenechitosan polymers. Journal of Inorganic and Organometallic Polymers and Materials, 28(3): 962-967.

Sap A, Tabakci B, Yilmaz A. 2012. Calix[4]arene-based mannich and schiff bases as versatile receptors for dichromate anion extraction: Synthesis and comparative studies. Tetrahedron, 68(42): 8739-8745

Sayin S, Ozcan F, Yilmaz M. 2011. Preparation and application of calix[4]arene derivatives bearing pyridinium units-grafted magnetite nanoparticles for removal of dichromate and arsenate anions. Journal of Macromolecular Science, Part A, 48(5): 365-372.

Sayin S, Yilmaz M, Tavasli M. 2011. Syntheses of two diamine substituted 1,3-distal calix[4]arene-based magnetite nanoparticles for extraction of dichromate, arsenate and uranyl ions. Tetrahedron, 67(20): 3743-3753.

Tabakci M, Yilmaz M. 2008. Synthesis of a chitosan-linked calix[4]arene chelating polymer and its sorption ability toward heavy metals and dichromate anions. Bioresource Technology, 99(14): 6642-6645.

Ugur A, Sener I, Alpoguz HK. 2015. The removal of zn(ii) through calix[4]recorcinarene derivative based polymer inclusion membrane from aqueous solution. Journal of Macromolecular Science, Part A, 52(10): 801-808.

Venkateswaran P, Gopalakrishnan AN, Palanivelu K. 2007. Di(2ethylhexyl) phosphoric acid-coconut oil supported liquid membrane for the separation of copper ions from copper plating wastewater. Journal of Environmental SciencesChina, 19(12): 1446-1453.

Wu XY, Cobbina SJ, Mao GH, Xu H, Zhang Z, Yang LQ. 2016. $A$ review of toxicity and mechanisms of individual and mixtures of heavy metals in the environment. Environmental Science and Pollution Research, 23(9): 8244-8259. 